\title{
HEALTH-RELATED QUALITY OF LIFE IN WOMEN WITH BREAST CANCER ATTENDING BASRAH ONCOLOGY CENTRE
}

\author{
Elaf Muhammad Saleh * , Narjes A. H. \# \\ ${ }^{*} \mathrm{PhD}$ Community Medicine - University of Basrah - College of Medicine - Iraq, \#PhD Professor Community Medicine - \\ University of Basrah - College of Medicine - Iraq
}

\begin{abstract}
Quality of life issues are increasingly being recognized as critical in the spectrum of cancer treatment that the prolongation of survival cannot be the only therapeutic objective. In some cases, patients and physicians may have to choose between the prospects of longer survival or better quality of life during the remaining time.

This is a cross sectional study carried out to measure health-related quality of life in 275 women with breast cancer attending Al-Basrah oncology center during six months period, data were collected through direct interview using the standard European Organization for Research and Treatment of Cancer Core Quality of Life Questionnaire (EORTC-C30) and its complementary questionnaire specific for breast cancer (QLQ -BR -23).

The study showed that the mean score for global QoLwas52.39 \pm 17.1 indicating that the patients had average scale score. The most important predictors of global QoL were physical, role, cognitive and sexual functions in addition to future perspective and arm symptoms.

In conclusion the most important determinants predicting global QOL were role, physical, cognitive and sexual functions in addition to future perspective and arm symptoms.
\end{abstract}

Keywords: Breast cancer, quality of Life (QoL), (EORTC-C30), (QLQ -BR -23).

\section{Introduction}

$\mathrm{B}$ reast cancer in women is a great medical problem and it is the most common cancer among women worldwide ${ }^{1}$. Globally the cases of breast cancer constitute $20 \%$ of all annually diagnosed cancer cases and $26 \%$ of new cancer cases among women ${ }^{2}$. Supposing present trends in incidence rates keep constant, there will be 2.7 million new cases worldwide in $2030^{3}$. During the years 20052008 breast cancer was the most common cancer in Basrah governorate; constitute $16.8 \%$ of all incident cancers and $30.2 \%$ of all cancer patients among women ${ }^{4}$. The number of breast cancer survivors increased with the advancement in tools that detect early breast cancer and development of novel multimodality therapies. So the quality of life challenges are more and more being established as critical in the scene of cancer therapy ${ }^{5}$. Therefore, the standard post-therapy follow-up monitoring of these patients should address long-term complications of therapy, quality-of-life issues, and routine medical care ${ }^{6}$. Consequently, avoidance of complications and improvement of function should be considered as early in the management course as possible. Breast cancer survivors often experience physical and psychosocial impairments that can negatively influence their quality of life. From the time of diagnosis, breast cancer patient and her family suffer a broad spectrum of emotions. Patients may have a deteriorated self-image due to mastectomy and an awareness of the loss of a sexually significant body part. Patients may also identify themselves as unappealing and withdraw from friends ${ }^{5}$.

Quality of life is defined by WHO as" an individual's insight of their position in life in the context of the culture and value systems in which they live and about their objectives, anticipations, standards, and affairs. It is a wide-ranging concept impacted in a complex way by the person's physical wellbeing, psychological state, degree of self-determination, social relations, and their relationships to prominent characteristics of their surroundings" 7 . Reviewing the literature on quality of life among survivors of breast cancer noted that both demographic and clinical variables, like the stage of breast cancer, duration of illness, educational status, employment, and marital status, may be determinants of cancer patients' quality of life $8,9,10,11,12,13,14$ along with other variables such as their ethnicity ${ }^{15}$ and residency ${ }^{16}$. The survival of women with metastatic breast cancer is often prolonged, the prevalence of the metastatic disease is high, and indeed, the care for women with metastatic breast cancer is a major challenge for oncol- 
ogists and palliative care teams ${ }^{17}$.

The present study was carried out to assess the impact of diagnosis and treatment of breast cancer on the quality of life of breast cancer patients attending Al-Basrah oncology centre and to identify the main predictors of functional and global quality of life scales.

\section{Patients and methods}

The present study is a cross-sectional study carried out in Al-Basrah oncology center during a period of 6 months extending from the 1st of January to the 30th of June, 2012. The subjects were female patients with confirmed histological diagnosis of breast cancer attending the outpatient clinic of AlBasrah oncology center during the study period. All women with breast cancer whether they were from Basrah or from other governorates who fulfilled the study's inclusion criteria were included.

A total of 275 female patients with breast cancer who consecutively attended Al-Basrah oncology outpatient clinic for treatment or follow-up were enrolled. . However, new patients who were attending the center for their first dose of chemotherapy or their duration of the disease was less than 2 months were excluded.

Basrah Health Directorate official agreement to carry out the study was obtained before starting the study. The data were collected from the enrolled women by direct private interviews by one of the researchers. Before the interviews patients gave verbal informed consent to participate in the study.

The standard European Organization for Research and Treatment of Cancer Core Quality of Life Questionnaire (EORTC QLQ-C30) and (QLQ-BR23) were used in this study. The scores for scales of the EORTC QLQ - C30 range from 0 to 100 . A high score for a functional scale represents a high / healthy level of functioning, a high score for the global health status / QoL represents a high QoL. But a high score for a symptom scale / item represents a high level of symptomatology / problems 18

The data were analyzed by the Statistical Package for Social Science (SPSS) version 15. Descriptive statistics like the socio-demographic \& clinical characteristics were presented as frequencies, and percentages. In addition multiple linear (stepwise) regression analysis was conducted to determine the predictors of global QoL and QLQ-C30 functional scales. P-value of $<0.05$ was the criterion of statistical significance.

\section{Results}

Socio-demographic characteristics of the study population. The age of the studied women ranged between $21-83$ years, the mean age was $48 \pm 10.3$ years; Table (1). The highest proportion of the study population were living in Basrah city center (40.4\%), 35.3\% in other districts in Basrah governorate and only $24.4 \%$ of the patients were from other governorates mainly from Thi-qar \& Missan

About two thirds of breast cancer patients were married (62.2\%), illiterate patients formed 37.1\% of the study population, while only $11.6 \%$ had higher education (studied for 13 years or more) Majority of the studied patients were housewives $(81.8 \%)$, while $14.9 \%$ of them were employed; Table (1).

Clinical characteristics: As for clinical characteristics of the study participants; the majority were diagnosed at stages II and III \& more than half of them had the disease for at least 2 years. According to the case records of the studied breast cancer cases, the vast majority underwent mastectomy and received chemotherapy; Table (2).

Quality of life: The mean score for the global health status for breast cancer patients in present study was52.39 \pm 17.1 . The best functional outcomes were found for the physical and role functioning subscales while emotional, cognitive \& social functioning scored the lowest. The mean scores for symptom scales are shown in Table (3). The worst symptom scales were those for insomnia, pain, fatigue, appetite loss and dyspnea. Better symptom scores were found for other symptoms like diarrhea, constipation, and nausea\& vomiting indicating that these symptoms were less severe. The majority $(83.3 \%)$ of breast cancer patients had financial difficulties.

Regarding BR-23 Scales, more than half (54.5\%) of the studied patients in present study had poor body image. They also had a relatively poor sexual functioning \&enjoyment. Similarly, a high percentage of the participants $(61.1 \%)$ had poor scoring in future perspective scale Table (4). The most intense symptom experienced by the studied women was hair loss followed by systemic therapy side effects and arm symptoms. 
Table (1) Socio-demographic Characteristics of the study population

\begin{tabular}{|c|c|c|}
\hline Variable & No. & $\%$ \\
\hline \multicolumn{3}{|l|}{ Age } \\
\hline$\leq 30$ & 7 & 2.5 \\
\hline $30-39$ & 45 & 16.4 \\
\hline $40-49$ & 88 & 32.0 \\
\hline $50-59$ & 90 & 32.7 \\
\hline$\geq 60$ & 45 & 16.4 \\
\hline \multicolumn{3}{|l|}{ Residence } \\
\hline Basrah City center & 111 & 40.4 \\
\hline Other Basrah districts & 97 & 35.2 \\
\hline Other governorates & 67 & 24.4 \\
\hline \multicolumn{3}{|l|}{ Marital status } \\
\hline Single & 24 & 8.7 \\
\hline Married & 171 & 62.2 \\
\hline Divorced/widowed & 80 & 29.1 \\
\hline \multicolumn{3}{|l|}{ Education (years) } \\
\hline Illiterate & 102 & 37.1 \\
\hline$\leq 6$ & 77 & 28.0 \\
\hline $7-12$ & 64 & 23.3 \\
\hline$\geq 13$ & 32 & 11.6 \\
\hline \multicolumn{3}{|l|}{ Occupation } \\
\hline House wife & 225 & 81.8 \\
\hline Employed & 41 & 14.9 \\
\hline Retired & 9 & 3.3 \\
\hline Total & 275 & 100 \\
\hline
\end{tabular}

Quality of life predictors: The results showed that role, physical, cognitive and sexual functions, future perspective and arm symptoms were significant predictors of global QoL of breast cancer patients. They explained $94.7 \%$ of the variability in QoL. Table (5).

With respect to functional scales; Physical functions of breast cancer patients were mainly determined by patients' age, fatigue, role function, body image, type of treatment and the overall perception of quality of life. These factors explained $97.3 \%$ of physical function. While role function was mainly determined by the severity of systemic therapy side effects, physical function, fatigue, nausea\& vomiting, breast symptoms, and the overall perception of quality of life. These factors explained $95.6 \%$ of role function. Cognitive function was affected only by emotional function and the overall perception of quality of life, which explained $62.9 \%$ of cognitive function. While emotional function was mainly determined by social and cognitive functions and future perspective, they explained $62.2 \%$ of emotional function of breast cancer patients. On the other hand, $72.6 \%$ of social function was explained by emotional and sexual functions in addition to dyspnea Table (5).

\section{Discussion}

The global QoL mean score in this study $(52.3 \pm 17.1)$ was higher than that reported for women with breast cancer in Kuwait ${ }^{13}$, (45.3 \pm 15.3 ) but lower than that in UAE ${ }^{19}$ and Korea ${ }^{20}$, 
Table (2) Clinical characteristics of the study population

\begin{tabular}{|c|c|c|}
\hline Variable & No. & $\%$ \\
\hline \multicolumn{3}{|l|}{ Family history of breast cancer } \\
\hline Yes & 46 & 16.7 \\
\hline No & 229 & 83.3 \\
\hline \multicolumn{3}{|l|}{ Family history of other cancers } \\
\hline Yes & 79 & 28.7 \\
\hline No & 196 & 71.3 \\
\hline \multicolumn{3}{|l|}{ Stage } \\
\hline 0 & 1 & 0.4 \\
\hline I & 13 & 4.7 \\
\hline II & 131 & 47.6 \\
\hline III & 91 & 33.1 \\
\hline IV & 39 & 14.2 \\
\hline \multicolumn{3}{|l|}{ Duration of disease (years) } \\
\hline$<1$ & 86 & 31.3 \\
\hline $1-5$ & 151 & 54.9 \\
\hline$>5$ & 38 & 13.8 \\
\hline \multicolumn{3}{|l|}{ Type of treatment } \\
\hline Chemotherapy alone & 16 & 5.8 \\
\hline Surgery+ chemotherapy & 85 & 30.9 \\
\hline Surgery+ chemo+ hormonal therapy & 109 & 39.6 \\
\hline Surgery + chemo + hormonal + radiotherapy & 65 & 23.6 \\
\hline Total & 275 & 100 \\
\hline
\end{tabular}

(74.6 \& 66.5) respectively, and similar to that for breast cancer patients in China (52.3) ${ }^{21}$.

The pattern was the same for physical and role functioning. On the other hand, emotional, cognitive\& social functioning scores in this study were less than those reported in Kuwait ${ }^{13}$, UAE ${ }^{19}$, Turkey ${ }^{11}$, and Iran ${ }^{12}$. This may indicate less social and institutional support to breast cancer patients in Basrah, which can help the patients to boost psychosocial wellbeing. Based upon these findings provision of supportive care to meet patients' individual requirements is instrumental in enhancing their quality of life and paying more attention for rehabilitation plans by holding consultation sessions for the patients and continuing nursing services for them. Consequently, the doctors and staff of the Basra Oncology Center must be trained in the near-term rehabilitation plan.

Regarding symptom scales of QLQ-C30, the most intense and more frequent three symptoms in this study were sleep disturbance, pain \& fatigue. This pattern generally agrees with that reported for breast cancer patients in other Arabian countries like Kuwait $\left({ }^{13}\right)$, UAE $\left({ }^{19}\right)$, and \& other European countries like UK $\left({ }^{9}\right)$, and Sweden. $\left({ }^{22}\right)$ The present study, however, indicated more intense symptoms for dyspnea \& appetite loss than those reported in several other studies, $(9,10,12,22)$, but these symptoms were less intense than among breast cancer patients in Kuwait ${ }^{13}$.

An important result in the present study was that the mean score for the financial impact of breast cancer $(82.7 \pm 32.7)$ was higher than that reported in all other reviewed studies 9, 10, 13, 19, 21, 22. This may be mainly due to the shortage in chemotherapy provided or made available for the patients by the oncology center; therefore, the patients had to pay a lot of money to buy very expensive chemo- 
Table (3) The mean, SD, and 95\% CI scores of the EORTC QLQ-C30

\begin{tabular}{|c|c|c|c|c|c|}
\hline Variables & Mean & SD & $95 \% \mathrm{Cl}$ & $\%$ of poor scoring & $\%$ of good scoring \\
\hline \multicolumn{6}{|l|}{ C-30 Functional scales* } \\
\hline Global QoL & 52.39 & 17.1 & $50.36-54.42$ & 20 & 28.4 \\
\hline Physical function & 75.7 & 25 & 72.74-78.68 & 8 & 74.5 \\
\hline Role function & 76.73 & 32.1 & $72.90-80.50$ & 13.5 & 73.8 \\
\hline Emotional function & 41.64 & 37.8 & $37.10-46.10$ & 52.4 & 33.1 \\
\hline Cognitive function & 43.59 & 36.4 & $39.27-47.90$ & 45.5 & 29.8 \\
\hline Social functioning & 44.79 & 40.5 & $39.97-49.60$ & 50.5 & 46.5 \\
\hline \multicolumn{6}{|l|}{ C-30 Symptoms scales\# } \\
\hline Fatigue & 34.3 & 29.4 & $30.80-37.80$ & 18.5 & 63.3 \\
\hline Nausea \& vomiting & 16 & 30 & $12.40-19.60$ & 10.2 & 81.1 \\
\hline Pain & 35.3 & 29.8 & $31.80-38.90$ & 18.2 & 54.5 \\
\hline Dyspnea & 26.2 & 37.1 & $21.80-30.60$ & 25.8 & 74.2 \\
\hline Sleep disturbance & 40.2 & 43.1 & $35.10-45.30$ & 38.5 & 61.5 \\
\hline Appetite loss & 27.9 & 39.8 & $23.10-32.60$ & 24.4 & 75.6 \\
\hline Constipation & 15.7 & 33.8 & $11.70-19.80$ & 15.6 & 84.4 \\
\hline Diarrhea & 13.7 & 30.8 & $10.00-17.30$ & 11.6 & 88.4 \\
\hline Financial impact & 82.7 & 32.7 & $78.70-86.50$ & 83.3 & 16.7 \\
\hline
\end{tabular}

* Scores range from 0 to 100 , with higher mean scores corresponding to better functioning.

\# Scores range from 0 to 100, with higher mean scores corresponding to more frequent \&\%or more intense symptoms

Table (4) The mean, SD, and 95\% CI scores of the BR-23

\begin{tabular}{||c|c|c|c|c|c||}
\hline Variables & Mean & SD & $95 \% \mathrm{Cl}$ & $\%$ of poor scoring & $\%$ of good scoring \\
\hline QoL - BR23: Functional scales* & \multicolumn{5}{|c||}{18.2} \\
\hline Body image & 60.4 & 42.5 & $55.4-65.5$ & 54.5 & 10.2 \\
\hline Sexual functioning\# & 44.4 & 21.3 & $39.9-48.9$ & 45.5 & 10.2 \\
\hline Sexual enjoyment\# & 37.0 & 26.2 & $31.5-42.5$ & 28.0 & 38.9 \\
\hline Future perspective & 34.8 & 42.9 & $25.8-43.8$ & 61.1 & \\
\hline BR23: Symptom scales\# & & & & 29.1 \\
\hline Upset by hair loss & 72.0 & 43.4 & $63.5-81.6$ & 53.5 & 22.5 \\
\hline Systemic side effects & 58.7 & 21.6 & $54.2-63.3$ & 34.5 & 59.6 \\
\hline Arm symptoms & 46.6 & 29.5 & $40.4-52.8$ & 28.4 & 8.4 \\
\hline Breast symptoms & 13.7 & 19.0 & $9.7-17.7$ & 4 & 2.7 \\
\hline
\end{tabular}

* Scores range from 0 to 100 , with higher mean scores corresponding to better functioning.

\# Scores range from 0 to 100, with higher mean scores corresponding to more frequent \& $\%$ or more intense symptoms

therapy. Regarding the Profile of BR-23 scores; for the functional scales of the BR-23, the mean score for body image was similar to that reported in Kuwait ${ }^{13}$, Iran ${ }^{12}$, \& China ${ }^{21}$. On the other hand, the results indicated worse sexual functioning for women with breast cancer in the present study compared to that for Iranian, Kuwaiti, and Emirati women ${ }^{12,13,19}$. However, sexual functioning in this study was better than that in UK, Korea \&
China, which may be related to cross-cultural variations $9,10,22$. For the symptom scales of BR-23, the mean scores indicated that women in this study had more intense symptoms than women from all the comparison countries for systemic side effects, arm symptoms \& upset by hair loss 9,10,12,13,19,22 . The pattern was the reverse for the breast symptoms, that women in this study had less intense breast symptoms than women from all the com- 
Table (5) Predictors of functional health status and global quality of life

\begin{tabular}{|c|c|c|c|c|}
\hline $\begin{array}{l}\text { Dependent } \\
\text { variable }\end{array}$ & $\begin{array}{c}\text { Independent } \\
\text { variables } \\
\text { (Predictors) }\end{array}$ & $\begin{array}{c}\text { Standardized } \\
\text { Coefficients }\end{array}$ & $P$ value & $\mathrm{R}^{2}$ \\
\hline \multirow{6}{*}{$\begin{array}{l}\text { Global } \\
\text { quality } \\
\text { of life }\end{array}$} & Role function & 0.290 & 0.001 & \multirow{6}{*}{0.947} \\
\hline & Physical function & 0.367 & 0.004 & \\
\hline & Cognitive function & 0.100 & 0.010 & \\
\hline & Sexual function & 0.119 & 0.025 & \\
\hline & Future perspective & 0.098 & 0.003 & \\
\hline & Arm symptoms & 0.094 & 0.020 & \\
\hline \multirow{6}{*}{ Physical function } & GQoL & 0.214 & 0.007 & \multirow{6}{*}{0.973} \\
\hline & Age & 0.603 & 0.000 & \\
\hline & Role function & 0.345 & 0.000 & \\
\hline & Body image & -0.077 & 0.009 & \\
\hline & Fatigue & -0.144 & 0.000 & \\
\hline & Type of treatment & 0.155 & 0.011 & \\
\hline \multirow{6}{*}{ Role function } & GQoL & 0.211 & 0.018 & \multirow{6}{*}{0.956} \\
\hline & Physical function & 0.531 & 0.000 & \\
\hline & Fatigue & 0.104 & 0.014 & \\
\hline & Nausea\& vomiting & -0.091 & 0.002 & \\
\hline & Systemic side effects & 0.274 & 0.000 & \\
\hline & Breast symptoms & -0.091 & 0.005 & \\
\hline \multirow{2}{*}{ Cognitive function } & GQoL & 0.588 & 0.000 & \multirow{2}{*}{0.629} \\
\hline & Emotional function & 0.266 & 0.004 & \\
\hline \multirow{3}{*}{$\begin{array}{l}\text { Emotional } \\
\text { function }\end{array}$} & Cognitive function & 0.311 & 0.001 & \multirow{3}{*}{0.622} \\
\hline & Social function & 0.317 & 0.000 & \\
\hline & Future perspective & 0.303 & 0.002 & \\
\hline \multirow{4}{*}{ Social function } & Physical function & 0.823 & 0.000 & \multirow{4}{*}{0.726} \\
\hline & Emotional function & 0.281 & 0.001 & \\
\hline & Dyspnea & 0.153 & 0.025 & \\
\hline & Sexual function & -0.329 & 0.005 & \\
\hline
\end{tabular}

parison countries except Iran ${ }^{12}$. These variations may be partly attributed to the lack of formal psycho-education and inappropriate preparation of the patients for toxicities of treatment. The highlight of regression analyses was that the functional scale scores were more important in predicting global QoL, than the scores of the symptom scales which may be due to the response-shift phenomenon ${ }^{23}$.
Socio-demographic characteristics and symptom scales of QLQ-C30 had no significant role as determinants for global QoL. These results disagree with the results of other studies ${ }^{13,24}$, which found that age, occupation\& pain predicted global QoL scores. Regarding BR-23 scales, this study found that sexual function, arm symptoms\& future perspective significantly predicted global QoL scores. 
These results agree with those reported in the $\mathrm{Ku}$ waiti study ${ }^{13}$.

\section{Conclusions}

About three quarter of the breast cancer patients in this study met the criterion for good functioning on physical\& role functioning scales. The most important determinants predicting global QOL were role, physical, cognitive and sexual functions in addition to future perspective and arm symptoms.

\section{Acknowledgments}

We would like to thank all senior doctors and staff of AL-Basrah oncology center, for their cooperation in obtaining data for the study. We are very grateful to all women who participated in the study and made the study possible.

\section{References}

1. International agency for research on cancer. Global cancer Facts \& Figures. 2nd ed. Atlanta: American cancer society; 2011.

2. Cavalli F, Kaye SB, Hansen HH, Armitage JO, Piccart-Gebhart MJ. Text book of medical oncology. 4th ed. United Kingdom: Informa Health Care; 2009.

3. Christopher IL. Breast cancer epidemiology. United State of America: Springer Science \&Business Media; 2010.

4. Basrah Cancer Research Group. Cancer in Basrah 2005-2008. Basrah: Dar Al-Kutub for press\& printing; 2010.

5. Hunt KK, Robb GL, Strom EA, Ueno NT. Breast cancer MD Anderson cancer series. 2nded. United State of America: Springer; 2008.

6. Manson BA, Lewis NL, Cianfrocca ME, Patel JD, Schilder RJ. MKSAP 15. United State of America: American college of physicians; 2009.

7. WHO, Division of Mental Health and Prevention of Substance Abuse. Measuring Quality of Life. The World Health Organization Quality of Life Instruments. Geneva; 1997. Available at WWW.Who.int/mental heath/media health/68.pdf. Accessed on $9 / 12 / 2012$.

8.Hopwood P, Haviland J, Mills J, Sumo G, Bliss J. The impact of age \& clinical factors on quality of life in early breast cancer: Analysis of 2208 women recruited to the UK START trial (standardization of breast radio therapy trial). The Breast 2007; $16(3): 241-251$.

9. Chae YR. Health-related quality of life in women with breast cancer in Korea: Do socio demographic characteristics \& time since diagnosis make difference? Oncology nursing forum 2010; 37(4):295-303.

10.Uzun O, Aslan FE, Selimen D, Koc M. Quality of life in women with breast cancer in turkey. J Nurs Scholar Sh 2004; 36(3):207-213.

11.. Harandy TF, Chofranipour F, Montazeri A, Anoosheh M, Mohammadi E, Ahmadi F. Health-related quality of life in Iranian breast cancer survivors :A qualitative study. Applied research quality of life 2010; 5:121-132.

12. Al-awadi SA, Ohaeri JU. Health-related quality of life of Kuwaiti women with breast cancer: A comparative study using EORTC quality of life questionnaire. BMC Cancer 2009; 9:222-233.

13. Al-Nagar RA, Nagi NM, Ali MM, Al-Muasli M. Quality of life among breast cancer patients in Yemen. Asian pac J prev 2011; 12(9):2335-2341.

14.Masmoudi A, Frikha M, Daoud J. Feasibility of quality of life assessment in routine clinical oncology practice: A Tunisian study. Eastern Mediterranean Health J 2009; 15(2):362-368.

15.Ashing-Giwa KT, Padella G, Tejero J, Karemer J, Wright K, Coscarelli A. Understanding the breast cancer experience of women: A qualitative study of African American, Asian American, Latina\& Caucasian cancer survivors. Psychology 2004; 13(6):408-428.

16.Ddisipio T, Hayes SC, Newman B, Aitken J, Janda M. Deos quality of life among breast cancer survivors one year after diagnosis differ depending on urban\&non urban residence? A comparative study. Health Qual life outcomes 2010; 8:3.

17.Mariotto AB, Etzioni R, Hurlbert M, Penberthy L, Mayer M. Estimation of the Number of Women Living with Metastatic Breast Cancer in the United States. Cancer Epidemiol Biomarkers Prev. 2017;26(6):809-815.

18. Fayers PM, Aaronson NK, Bjordal K, Groenvold M, Curran D, Bottomley A. On behalf of the EORTC Quality of Life Group. The EORTC QLQ - C30 Scoring Manual. Brussels: European Organization for Research and Treatment of Cancer; 2001.

19. Awad MA, Denic S, El Taji K. Validation of the European Organization for Research and Treatment in Cancer Quality of Life Questionnaire for Arabic - speaking populations. Ann NY AcadSci 2008; 1138:146-154.

20. Yun YH, Bae SH, Kang IO, Shin KH, Lee R, Kwon SI. Cross-cultural application of the Korean version of the European Organization for Research and Treatment of Cancer (EORTC) Breast-Cancer-Specific Quality of Life Questionnaire (EORTC QLQ-BR23)Support Care. Cancer 2004; 12:441-445.

21. Wan C, Meng Q, Yang Z, Tu X, Feng C, Tang X. Validation of the simplified Chinese version of EORTC QLQ-C30 from the measurements of five types of inpatients with cancer. Ann Oncol 2008; 19:2053-2060.

22.Derogar M, Schaaf MV, Lagergren P. Reference values for EROTC QLQ-C30 quality of life questionnaire in random sample of Swedish population. Actaoncologica 2012; 51:10-16.

23. Park BW, Lee S, Lee AR, Lee KH, Hwang SY. Quality of Life Differences between Younger and Older Breast Cancer Patients. J Breast Cancer 2011; 14(2): 112-118.

24. Safaee A, Moghimi-Dehkordi B, Zeighami B, Tabatabaee HR, Pourhoseingholi MA. Predictors of quality of life in breast cancer patients under chemotherapy. Indian Journal of Cancer 2008; 45 (3):107-1011. 